Terceiro Setor

\& Gestão

DOI: 10.33947/1982-3290-v13n1-2023

\title{
IMPLANTAÇÃO E ADEQUAÇÃO DA NORMA REGULAMENTADORA NR12 EM SETORES DE PRENSAS E INJETORAS DE ALUMÍNIO
}

\section{IMPLEMENTATION AND ADEQUACY OF NR12 REGULATORY STANDARDS IN PRESSES AND ALUMINUM INJECTORS}

David Coccuzzo ${ }^{1}$

\section{RESUMO}

O presente estudo tem por finalidade a verificação e estudo da norma regulamentadora NR12 aplicada a indústria metalúrgica voltada a injeção de peças em alumínio e suas ligas. E com isto selecionar as melhores técnicas de identificação, aplicação e redução da exposição do trabalhador aos riscos de acidentes e doenças ocupacionais.

PALAVRAS-CHAVE: Norma. Prensa. Injetora. Aluminio.

\section{ABSTRACT}

This study aims to check and study the NR12 regulatory standard applied metallurgical industry facing the injection of parts in aluminum and its alloys. And with that select best identification techniques, application and reduced worker exposure to risks of accidents and occupational diseases

KEYWORDS: Standard. Press. Injector. Aluminium

1 Engenheiro Mecânico, Pós graduando em Engenharia de Segurança do Trabalho, pela Universidade UNG, www.ung.br. e-mail: david.coccuzzo@gmail.com 


\section{INTRODUÇÃO}

O gerenciamento da norma regulamentadora NR12 segurança no trabalho em máquinas e equipamentos está no centro da agenda industrial. No Brasil a preocupação com a segurança no trabalho é recente, sendo ainda hoje, grande parte das indústrias de pequeno e médio porte ainda não exercerem em sua integralidade esta norma regulamentadora.

As máquinas e equipamentos de fabricação anteriores a esta norma regulamentadora devem receber adequações a esta norma de tal forma e prazo que atendam a legislação pertinente trazendo conforto, segurança e otimização ao trabalho tornando-o seguro.

Norma regulamentadora NR12 está baseada em uma lei, ou seja, é a regulamentação de uma lei, é de caráter obrigatório, tem a finalidade de estabelecer requisitos técnicos e legais sobre os aspectos mínimos de segurança e saúde do trabalho. $O$ não cumprimento pode acarretar a aplicação das penalidades previstas na legislação pertinente.

A Norma Regulamentadora NR 12, encontra-se disponível para maior abrangência e conhecimento de todos, no site do Ministério do Trabalho e Emprego conforme o endereço: http://portal.mte.gov.br/legislacao/normas-regulamentadoras-1.htm.

\section{EMBASAMENTO}

\subsection{Procedimentos para adequação da norma regulamentadora NR-12}

\section{$1^{\circ}$ Passo}

Inventário das Máquinas e Equipamentos localizados em Planta Baixa de acordo com a NR-12 o empregador deve manter o inventário das máquinas e equipamentos atualizado com as devidas identificações e com a localização em planta baixa (layout), para que as mesmas sejam analisadas e adequadas conforme a NR-12. O empregador deve manter inventário atualizado das máquinas e equipamentos com identificação por tipo, capacidade, sistemas de segurança e localização em planta baixa, elaborado por profissional qualificado ou legalmente habilitado. 12.153.1. As informações do inventário devem subsidiar as ações de gestão para aplicação desta Norma.

\section{$2^{\circ}$ Passo}

Análise de Riscos: apreciação de riscos deve ser elaborada, executada por um profissional legalmente habilitado o qual realizará a análise de riscos de todo o sistema de segurança das máquinas e equipamentos, analisando todo o sistema elétrico, eletrônico, pneumático, hidráulico e mecânico. A análise de riscos ocorre de forma sistemática, e tem o objetivo de informar quais são os riscos e sua categoria do risco, quais as medidas de prevenção ou proteção que existem, ou deveriam existir para controlar os riscos, quais as possibilidades dos perigos serem eliminados, e quais são as partes da máquinas e equipamentos que estão sujeitos a causar lesões e danos.

Pode-se ressaltar parte da NR 12, ou seja:

12.39. Os sistemas de segurança devem ser selecionados e instalados de modo a atender aos seguintes requisitos:

a) ter categoria de segurança conforme prévia análise de riscos prevista nas normas técnicas oficiais vigentes; b) estar sob a responsabilidade técnica de profissional legalmente habilitado; c) possuir conformidade técnica com o sistema de comando a que são integrados; d) instalação de modo que não possam ser neutralizados ou burlados; e) manterem-se sob vigilância automática, ou seja, monitoramento, de acordo com a categoria de segurança requerida, exceto para dispositivos de segurança exclusivamente mecânicos; e f) paralisação dos movimentos perigosos e demais riscos quando ocorrerem falhas ou situações anormais de trabalho."

Normas para elaboração da Análise de Riscos com base nas normas técnicas oficiais e vigentes para a apreciação de riscos são: NBR ISO 12100:2013; ISO/TR 14121-2:2012 - Safety of machinery - Risk assessment - Part 2: Practical guidance and examples of methods.14121, e para a categorização do sistema de segurança a NBR 
14153, NBR ISO 12100:2013 Segurança de máquinas - Princípios gerais de projeto - Apreciação e redução de riscos; ISO/TR 14121-2:2012 - Safety of machinery - Risk assessment - Part 2: Practical guidance and examples of methods.; NBR 14153:2013 - Segurança de Máquinas - Partes de sistemas de comando relacionados à segurança - Princípios gerais para o projeto.

É comum uma mesma máquina ou equipamento ter mais de uma categoria de riscos, em diferentes partes, por isso deve ser feita análise de riscos em todo o perímetro da máquina ou equipamento, considerando os riscos durante a operação e manutenção. Feita a Análise de Riscos é fundamental que se crie um plano de ação, como por exemplo: Quais são as categorias de risco? Quais dispositivos serão incorporados? Refaça o projeto do equipamento acrescentando os dispositivos de segurança. Quanto custará as modificações? Quanto tempo levará para a adequação? Tendo essas informações é possível negociar um outro prazo para adequação junto ao fiscal do Ministério do Trabalho e Emprego (MTE) em caso de autuação, uma vez que todos os prazos estipulados na portaria $N^{\circ} 197$, de 17 de dezembro de 2010 já se esgotaram.

\section{$3^{\circ}$ Passo}

A Anotação de Responsabilidade Técnica ART do profissional legalmente habilitado responsável pela elaboração, execução da apreciação de riscos deve recolher a ART no Conselho Regional de Engenharia e Agronomia CREA de sua região, para que a análise de risco esteja sob sua responsabilidade técnica, conforme a NR-12: Item 12.39: a) ter categoria de segurança conforme prévia análise de riscos prevista nas normas técnicas oficiais vigentes; $b$ ) estar sob a responsabilidade técnica de profissional legalmente habilitado.

O termo ART significa Anotação de Responsabilidade Técnica, é um instrumento indispensável para identificar a responsabilidade técnica pelas obras ou serviços prestados por profissionais ou empresas.

AAnotação de Responsabilidade Técnica - ART, foi instituída pela Lei $n^{\circ} 6.496$, de 7 de dezembro de 1977, a qual estabelece que todos os contratos referentes à execução de serviços ou obras de Engenha- ria, Agronomia, Geologia, Geografia ou Meteorologia deverão ser objeto de anotação no Conselho Regional de Engenharia e Agronomia - CREA.

De acordo com a Lei n 6.496/77 na íntegra no Anexo C

Conforme estabelece a Resolução $n^{\circ} 1.025$, de 2009, do CONFEA, fica sujeito à anotação de responsabilidade técnica no CREA em cuja circunscrição for exercida a respectiva atividade: - Todo contrato referente à execução de obras ou prestação de serviços relativos às profissões vinculadas à Engenharia, Agronomia, Geologia, Geografia ou Meteorologia; Todo vínculo de profissional com pessoa jurídica para o desempenho de cargo ou função que envolva atividades para as quais sejam necessários habilitação legal e conhecimentos técnicos nas profissões retro mencionadas. A anotação é feita por meio do formulário eletrônico disponível no CREA na Internet. Nele são declarados os principais dados do contrato firmado entre o profissional e seu cliente (no caso de profissional autônomo), ou ainda entre o contratado e o contratante (no caso de profissional com vínculo empregatício).

Término da Adequação: Ao terminar a apreciação de riscos, após todos os perigos e riscos identificados e com a devida ART recolhida junto ao CREA, será necessário elaborar um plano de ação para adequar todo o parque de máquinas conforme a NR-12, e executar as alterações pertinentes identificadas na prévia análise de riscos.

Importante: Todos os trabalhos de adequações e implementações executados nas máquinas e equipamentos referentes as exigências da Norma Regulamentadora NR-12, serão de grande valia se forem documentados tanto na forma escrita como na forma ilustrativa, informando quais os componentes e proteções que foram instalados, sejam no âmbito elétrico, eletrônico, mecânico, pneumático ou hidráulico. Relatar tudo o que foi executado na máquina e equipamento, ilustrando com fotos do antes e depois das adequações e mantê-los juntos aos documentos de projeto da máquina e equi- 
pamento, análise de riscos e ART, para que desta forma obtenha-se um conjunto de documentos dos quais comprovem as adequações executadas nas máquinas e equipamentos conforme as exigências da Norma regulamentadora NR-12.

As máquinas e os equipamentos e seus respectivos sistemas de segurança, seja elétrico, eletrônico, mecânico, pneumático ou hidráulico devem ser elaborados, projetados conforme as exigências da norma regulamentadora NR-12 e normas técnicas oficiais vigentes. Devem possuir características mínimas de segurança as quais são de uso geral, e características especificas para o determinado tipo de máquina e equipamento. Algumas das Normas técnicas oficiais vigentes de segurança em máquinas e equipamentos, estão ilustradas no slide 32 e estão classificadas como normas do tipo A: definem os conceitos, princípios de projetos e aspectos gerais de segurança, normas do tipo B (B1 e B2): Aspectos e componentes de segurança e normas do tipo $C$ : fornecem prescrições detalhadas de segurança a um grupo particular de máquinas.

Deve-se elaborar a Análise de Riscos do sistema de segurança das máquinas e equipamentos, que tem como objetivo informar quais são os riscos que as máquinas e equipamentos oferecem, qual é a categoria do risco, quais as medidas de prevenção ou proteção que existem, ou deveriam existir para controlar os riscos, quais as possibilidades dos perigos serem eliminados, quais são as partes da máquina e equipamento que estão sujeitos a causar lesões e danos, e executar as adequações conforme a Apreciação de Riscos. Deve conter juntamente com a Análise de Riscos a ART - Anotação de Responsabilidade Técnica, a qual responsabiliza o profissional legalmente habilitado por sua análise.

Devem ser elaborados detalhadamente, todos os procedimentos de trabalho e segurança das máquinas e equipamentos conforme está descrito na NR-12. NR-12 (Procedimentos de trabalho e segurança 12.130). Devem ser elaborados procedimentos de trabalho e segurança específicos, padronizados, com descrição detalhada de cada tarefa, passo a passo, a partir da análise de risco. 12.130.1. Os procedimentos de trabalho e segurança não podem ser as únicas medidas de proteção adotadas para se prevenir acidentes, sendo considerados complementos e não substitutos das medidas de proteção coletivas necessárias para a garantia da segurança e saúde dos trabalhadores. 12.131. Ao início de cada turno de trabalho ou após nova preparação da máquina ou equipamento, o operador deve efetuar inspeção rotineira das condições de operacionalidade e segurança e, se constatadas anormalidades que afetem a segurança, as atividades devem ser interrompidas, com a comunicação ao superior hierárquico.

\subsection{Procedimentos de Trabalho e Segurança da NR12}

12.132. Os serviços em máquinas e equipamentos que envolvam risco de acidentes de trabalho devem ser planejados e realizados em conformidade com os procedimentos de trabaIho e segurança, sob supervisão e anuência expressa de profissional habilitado ou qualificado, desde que autorizados. 12.132.1. Os serviços em máquinas e equipamentos que envolvam risco de acidentes de trabalho devem ser precedidos de ordens de serviço - OS - específicas, contendo, no mínimo: a) a descrição do serviço; b) a data e o local de realização; c) o nome e a função dos trabalhadores; e d) os responsáveis pelo serviço e pela emissão da OS, de acordo com os procedimentos de trabalho e segurança.

Os trabalhadores envolvidos com a máquina e equipamento na operação, manutenção, inspeção entre outras atividades devem ser capacitados, conforme está descrito na NR-12. NR-12 (Capacitação 12.135). A operação, manutenção, inspeção e demais intervenções em máquinas e equipamentos devem ser realizadas por trabalhadores habilitados, qualificados, capacitados ou autorizados para este fim conforme subtópicos da norma regulamentadora NR12 abaixo:

12.136. Os trabalhadores envolvidos na operação, manutenção, inspeção e demais intervenções em máquinas e equipamentos devem receber capacitação providenciada pelo empregador e compatível com suas funções, que 
aborde os riscos a que estão expostos e as medidas de proteção existentes e necessárias, nos termos desta Norma, para a prevenção de acidentes e doenças.

12.137. Os operadores de máquinas e equipamentos devem ser maiores de dezoito anos, salvo na condição de aprendiz, nos termos da legislação vigente.

12.138. A capacitação deve:

a) ocorrer antes que o trabalhador assuma a sua função;

b) ser realizada pelo empregador, sem ônus para o trabalhador;

c)ter carga horária mínima que garanta aos trabalhadores executarem suas atividades com segurança, sendo distribuída em no máximo oito horas diárias e realizada durante o horário normal de trabalho;

d) ter conteúdo programático conforme o estabelecido no Anexo II desta Norma; e

e)ser ministrada por trabalhadores ou profissionais qualificados para este fim, com supervisão de profissional legalmente habilitado que se responsabilizará pela adequação do conteúdo, forma, carga horária, qualificação dos instrutores e avaliação dos capacitados.

12.139. O material didático escrito ou audiovisual utilizado no treinamento e o fornecido aos participantes, devem ser produzidos em linguagem adequada aos trabalhadores, e ser mantidos à disposição da fiscalização, assim como a lista de presença dos participantes ou certificado, currículo dos ministrantes e avaliação dos capacitados.

12.140. Considera-se trabalhador ou profissional qualificado aquele que comprovar conclusão de curso específico na área de atuação, reconhecido pelo sistema oficial de ensino, compatível com o curso a ser ministrado.

12.141. Considera-se profissional legalmente habilitado para a supervisão da capacitação aquele que comprovar conclusão de curso específico na área de atuação, compatível com o curso a ser ministrado, com registro no competente conselho de classe.

12.142. A capacitação só terá validade para o empregador que a realizou e nas condições estabelecidas pelo profissional legalmente habilitado responsável pela supervisão da capacitação. 12.142.1. Fica dispensada a exigência do item 12.142 para os operadores de injetoras com curso de capacitação conforme o previsto no item 12.147 e seus subitens. 12.143. São considerados autorizados os trabalhadores qualificados, capacitados ou profissionais legalmente habilitados, com autorização dada por meio de documento formal do empregador.

12.143.1. Até a data da vigência desta Norma, será considerado capacitado o trabalhador que possuir comprovação por meio de registro na Carteira de Trabalho e Previdência Social CTPS ou registro de empregado de pelo menos dois anos de experiência na atividade e que receba reciclagem conforme o previsto no item 12.144 desta Norma.

12.144. Deve ser realizada capacitação para reciclagem do trabalhador sempre que ocorrerem modificações significativas nas instalações e na operação de máquinas ou troca de métodos, processos e organização do trabalho.

12.144.1. O conteúdo programático da capacitação para reciclagem deve atender às necessidades da situação que a motivou, com carga horária mínima que garanta aos trabalhadores executarem suas atividades com segurança, sendo distribuída em no máximo oito horas diárias e realizada durante o horário normal de trabalho.

12.145. A função do trabalhador que opera e realiza intervenções em máquinas deve ser anotada no registro de empregado, consignado em livro, ficha ou sistema eletrônico e em sua Carteira de Trabalho e Previdência Social - CTPS.

\section{3 - Capacitação}

A capacitação para atendimento a norma regulamentadora NR12 é parte integrante e principal para erradicação e ou minimização dos riscos inerentes ao trabalho com prensas e injetoras de alumínio conforme tópicos da norma a seguir:

12.147. O curso de capacitação para operado- 
res de máquinas injetoras deve possuir carga horária mínima de oito horas por tipo de máquina citada no Anexo IX desta Norma. 12.147.1. O curso de capacitação deve ser específico para o tipo máquina em que o operador irá exercer suas funções e atender ao seguinte conteúdo programático: a) histórico da regulamentação de segurança sobre a máquina especificada; b) descrição e funcionamento; c) riscos na operação; d) principais áreas de perigo; e) medidas e dispositivos de segurança para evitar acidentes; f) proteções - portas, e distâncias de segurança; g) exigências mínimas de segurança previstas nesta Norma e na NR 10; h) medidas de segurança para injetoras elétricas e hidráulicas de comando manual; e i) demonstração prática dos perigos e dispositivos de segurança.

12.147.2. O instrutor do curso de capacitação para operadores de injetora deve, no mínimo, possuir: a) formação técnica em nível médio; b) conhecimento técnico de máquinas utilizadas na transformação de material plástico; c) conhecimento da normatização técnica de segurança; e d) capacitação específica de formação.

\subsection{Sinalização}

A perfeita sinalização para atendimento a norma regulamentadora NR12 traz um grande facilitador para orientação e execução correta da operação em máquinas e equipamentos como prensas e injetoras de alumínio conforme sequencia dos subtópicos da norma regulamentadora NR12 abaixo:

12.116. As máquinas e equipamentos, bem como as instalações em que se encontram, devem possuir sinalização de segurança para advertir os trabalhadores e terceiros sobre os riscos a que estão expostos (foto1), as instruções de operação e manutenção e outras informações necessárias para garantir a integridade física e a saúde dos trabalhadores.

12.116.1. A sinalização de segurança compreende a utilização de cores, símbolos, inscrições, sinais luminosos ou sonoros, entre outras formas de comunicação de mesma eficácia. 12.116.2. A sinalização, inclusive cores, das máquinas e equipamentos utilizados nos setores alimentícios, médico e farmacêutico deve respeitar a legislação sanitária vigente, sem prejuízo da segurança e saúde dos trabalhadores ou terceiros.

12.116.3. A sinalização de segurança deve ser adotada em todas as fases de utilização e vida útil das máquinas e equipamentos.

12.117. A sinalização de segurança deve: a) ficar destacada na máquina ou equipamento; b) ficar em localização claramente visível; e c) ser de fácil compreensão. 12.118. Os símbolos, inscrições e sinais luminosos e sonoros devem seguir os padrões estabelecidos pelas normas técnicas nacionais vigentes e, na falta dessas, pelas normas técnicas internacionais. 12.119. As inscrições das máquinas e equipamentos devem: a) ser escritas na língua portuguesa - Brasil; e b) ser legíveis. 12.119.1. As inscrições devem indicar claramente o risco e a parte da máquina ou equipamento a que se referem, e não deve ser utilizada somente a inscrição de "perigo".

12.120. As inscrições e símbolos devem ser utilizados nas máquinas e equipamentos para indicar as suas especificações e limitações técnicas. 12.121. Devem ser adotados, sempre que necessário, sinais ativos de aviso ou de alerta, tais como sinais luminosos e sonoros intermitentes, que indiquem a iminência de um acontecimento perigoso, como a partida ou a velocidade excessiva de uma máquina, de modo que: a)sejam emitidos antes que ocorra o acontecimento perigoso; b) não sejam ambíguos; c) sejam claramente compreendidos e distintos de todos os outros sinais utilizados; e d) possam ser inequivocamente reconhecidos pelos trabalhadores.

12.122. Exceto quando houver previsão em outras Normas Regulamentadoras, devem ser adotadas as seguintes cores para a sinalização de segurança das máquinas e equipamentos:

a) amarelo: 1. proteções fixas e móveis - exceto quando os movimentos perigosos estiverem en- 
clausurados na própria carenagem ou estrutura da máquina ou equipamento, ou quando tecnicamente inviável; 2. componentes mecânicos de retenção, dispositivos e outras partes destinadas à segurança; 3 . gaiolas das escadas, corrimãos e sistemas de guarda-corpo e rodapé. b) azul: comunicação de paralisação e bloqueio de segurança para manutenção.

12.123. As máquinas e equipamentos fabricados a partir da vigência desta Norma devem possuir em local visível as informações indeléveis, contendo no mínimo: a) razão social, CNPJ e endereço do fabricante ou importador; b) informação sobre tipo, modelo e capacidade; c) número de série ou identificação, e ano de fabricação; d) número de registro do fabricante ou importador no CREA; e e) peso da máquina ou equipamento. 12.124. Para advertir os trabalhadores sobre os possíveis perigos, devem ser instalados, se necessários, dispositivos indicadores de leitura qualitativa ou quantitativa ou de controle de segurança. 12.124.1. Os indicadores devem ser de fácil leitura e distinguíveis uns dos outros.

Os manuais das máquinas e equipamentos devem ser escritos na língua portuguesa - Brasil, ser claros e objetivos, possuir procedimentos de utilização da máquina ou equipamento com segurança, entre outros requisitos conforme as exigências da NR-12. Veja as exigências da NR-12 relacionadas aos manuais. Manuais 12.125. As máquinas e equipamentos devem possuir manual de instruções fornecido pelo fabricante ou importador, com informações relativas à segurança em todas as fases de utilização. 12.126. Quando inexistente ou extraviado, o manual de máquinas ou equipamentos que apresentem riscos deve ser reconstituído pelo empregador, sob a responsabilidade de profissional legalmente habilitado.

12.127. Os manuais devem:

a) ser escritos na língua portuguesa - Brasil, com caracteres de tipo e tamanho que possibilitem a melhor legibilidade possível, acompanhado das ilustrações explicativas; b) ser objetivos, claros, sem ambiguidades e em linguagem de fácil compreensão; c) ter sinais ou avisos referentes à segurança realçados; e d) permanecer disponíveis a todos os usuários nos locais de trabalho.

12.128. Os manuais das máquinas e equipamentos fabricados ou importados a partir da vigência desta Norma devem conter, no mínimo, as seguintes informações: a) razão social, CNPJ e endereço do fabricante ou importador; b) tipo, modelo e capacidade; c) número de série ou número de identificação e ano de fabricação; d) normas observadas para o projeto e construção da máquina ou equipamento; e) descrição detalhada da máquina ou equipamento e seus acessórios; f) diagramas, inclusive circuitos elétricos, em especial a representação esquemática das funções de segurança; g) definição da utilização prevista para a máquina ou equipamento; h) riscos a que estão expostos os usuários, com as respectivas avaliações quantitativas de emissões geradas pela máquina ou equipamento em sua capacidade máxima de utilização; i) definição das medidas de segurança existentes e daquelas a serem adotadas pelos usuários; j) especificações e limitações técnicas para a sua utilização com segurança; k) riscos que podem resultar de adulteração ou supressão de proteções e dispositivos de segurança; I) riscos que podem resultar de utilizações diferentes daquelas previstas no projeto; $\mathrm{m}$ ) procedimentos para utilização da máquina ou equipamento com segurança; $n$ ) procedimentos e periodicidade para inspeções e manutenção; o) procedimentos a serem adotados em situações de emergência; $p$ ) indicação da vida útil da máquina ou equipamento e dos componentes relacionados com a segurança. 12.129. No caso de máquinas e equipamentos fabricados ou importados antes da vigência desta Norma, os manuais devem conter, no mínimo, as informações previstas nas alíneas "b", “e”, “f”, “g”, “i”, “j”, “k”, “l”, “m”, "n" e "o" do item 12.128. 


\section{REVISTA}

Terceiro Setor

\& Gestão
IMPLANTAÇÃO E ADEQUAÇÃO DA NORMA REGULAMENTADORA NR12 EM SETORES DE PRENSAS E INJETORAS DE ALUMÍNIO

\subsection{Componentes Padronizados de Segurança Adequados a NR12}

Foto 1 - Parte eletrônica

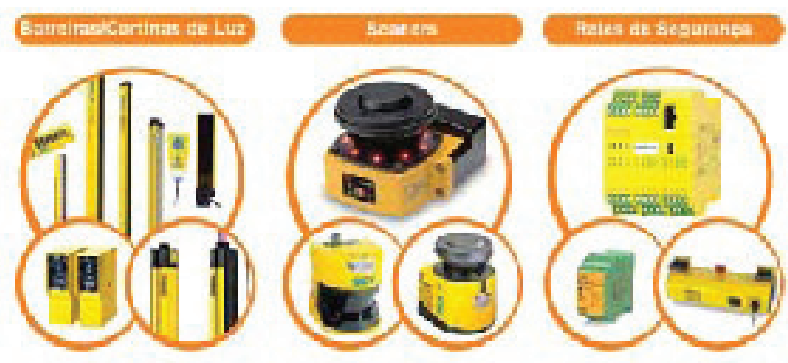

fonte: www.partenereletronica.com.br

Foto 2 - Barreira de luz montada em carrossel de usinagem

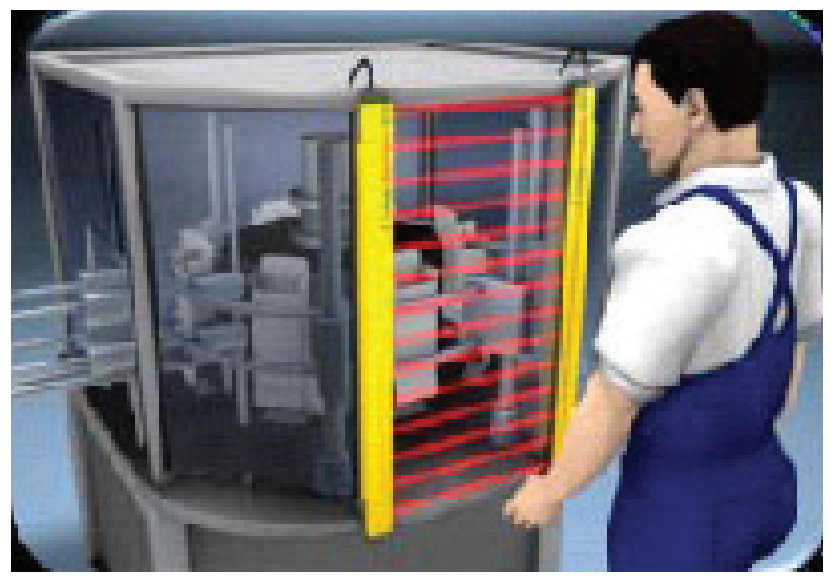

fonte: www.jdjautomacao.com.br

Foto 3 - Grade de proteção com barreira de luz em volta de Robô manipulador

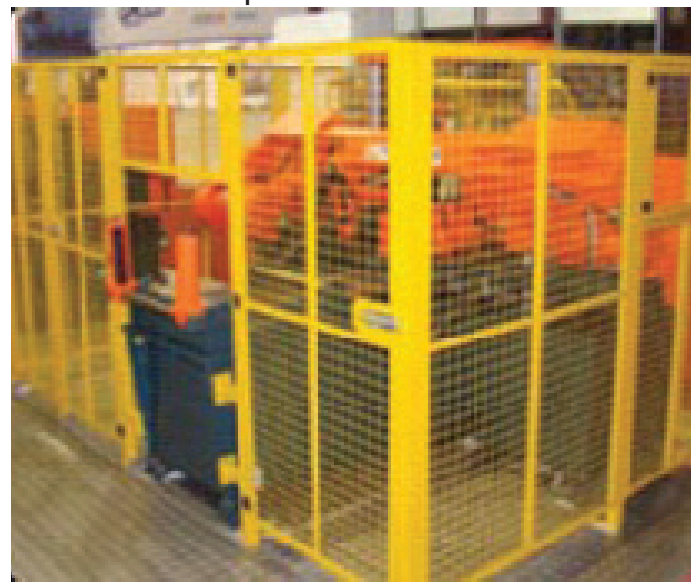

fonte: www.kadoshautomacao.com.br
Foto 4 - Prensa tipo "C" com barreira de luz e acionamento bi- manual e proteções laterais adequadas a NR 12

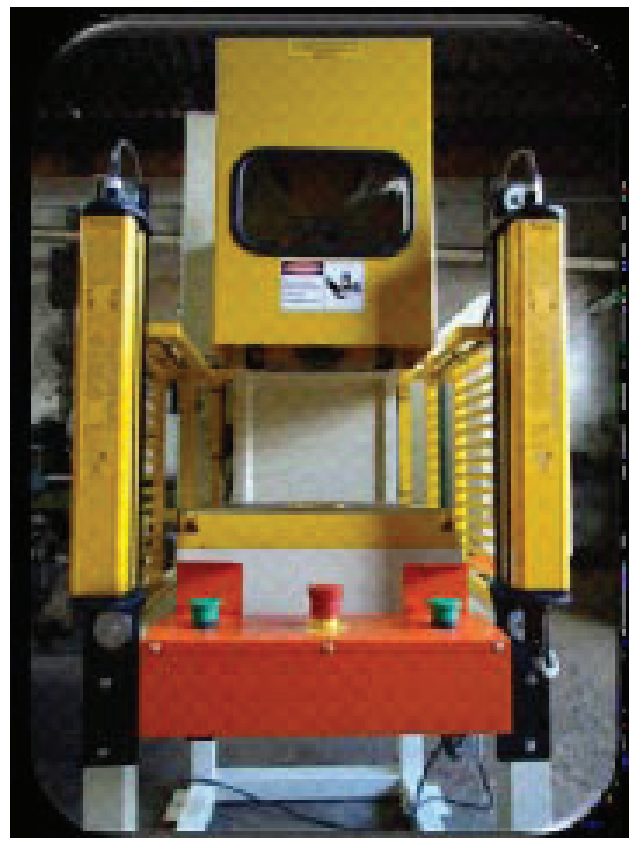

fonte:www.preciolandia.com

Foto 5 - Célula de produção de chapa de aço fabricando componentes automotivos estampados com grade de proteção e todos componentes de segurança adequados a NR 12

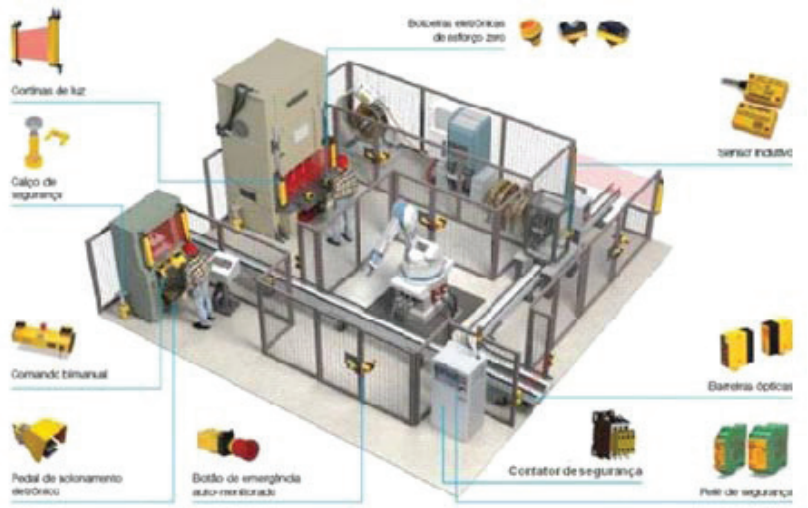

fonte: www.abimaq.org.br 
Foto 6 - Injetora de alumínio (similar a uma prensa horizontal) adequada a NR12 com bi-manual, porta com intertravamento, clp e bloco hidráulico auto travante

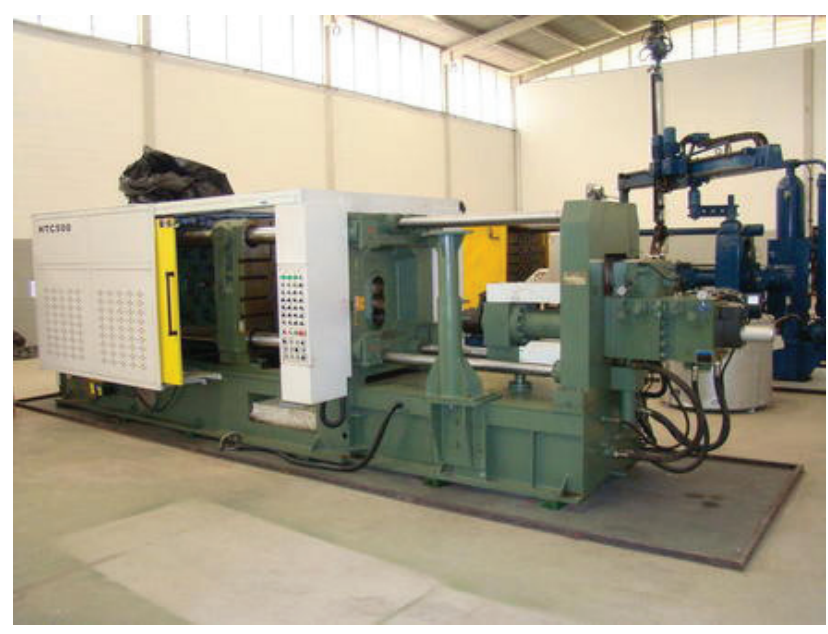

Fonte:www.sp.quebarato.com.br

\section{O PROBLEMA}

Devido aos riscos operacionais decorrentes da utilização de máquinas em não conformidade à norma NR 12, conduz à adequação de máquinas antigas e novas, estendendo-se à formatação de procedimentos estruturados e a necessidade de acompanhamento por Engenheiros de Segurança do Trabalho, com toda lisura em busca do êxito na transformação de máquinas e operações em condições seguras para o trabalho.

Com base neste conceito a formatação de check-list prático, operacional e em conformidade com as necessidades e apontamento da NR12 facilitará aos engenheiros de segurança do trabalho a execução do trabalho para adequação dos maquinários existentes e dos novos equipamentos rumo à operação segura.

\section{A SOLUÇÃO}

Como solução para a proteção adequada aos trabalhadores e com o intuito de atendimento a NR12, segue com a elaboração de um formulário prático para checagem destes maquinários, identificação dos potenciais riscos e as medidas para mitigá-los favorece a execução das implementações e adaptações. Através da elaboração de check-list e planilhas contendo as análises de riscos inerentes a operação com os maquinários e equipamentos objeto da análise, consegue-se identificar os potenciais de riscos e as falhas na obediência a norma regulamentadora NR12.

\subsection{Educação Operacional}

Há comunicação humana e o processo que envolve a troca de informações e utiliza os processos simbólicos como suporte. Está envolvida neste processo uma infinidade de maneiras de se comunicar. Por exemplo: duas pessoas falando face a face, ou através de gestos com as mãos, mensagens pelas redes sociais, telecomunicações, a fala, a escrita, que permitem interagir com outras pessoas e efetuar algum tipo de troca de informação. A habilidade mais usada na comunicação e o saber ouvir, portanto o bom comunicador deve também, além de saber se comunicar verbalmente, saber ouvir seu interlocutor.

Desta forma para que seja colocada em prática as intervenções necessárias ao atendimento da NR12 o treinamento se torna parte extremamente importante. O entendimento do perfeito funcionamento dos componentes lingados a NR12 tais como barreiras de luz, bi manuais, chaves com Inter travamento e etc.

Os fabricantes e importadores por meio de seus revendedores, deverão disponibilizar treinamento e material didático com conteúdo programático relativo a utilização segura do equipamento e deverá constar no manual de instruções. Os empregadores deverão disponibilizar a todos os operadores usuários deste maquinário também treinamento de utilização segura do equipamento. Deverá constar no certificado de garantia do equipamento o treinamento de operação segura e a responsabilidade do fabricante por este treinamento.

\section{CONSIDERAÇÕES FINAIS}

A portaria número 12/83 sobre proteção das máquinas sob o decreto 1.255 de 29 de dezembro de 1994 e convenção da Organização Internacional do Trabalho OIT número 119 trouxe ao trabalho de máquinas e equipamentos entre estes os de objeto 
do artigo (prensa e injetoras de alumínio) o melhor conhecimento dos riscos e consequentemente por meio de um trabalho de conscientização, tanto de operadores como de empresários, fabricantes de máquinas e usuários, uma melhor disposição para o uso visando a prevenção dos riscos de acidentes.

Desta forma a elaboração de planilha de análise dos movimentos das máquinas e seus riscos, visando o entendimento e mitigação e ou eliminação destes riscos levou órgãos como: MPE, ABIMAC e
Sindicatos de categorias tanto patronais como de empregados.

Assim o relatório abordado neste artigo possui sistemática simples e eficaz de forma a facilitar o trabalho de Engenheiros de Segurança do Trabalho, empresas e operadores a identificação dos riscos, mitigação e eliminação dos mesmos tornando o trabalho em máquinas deste segmento extremamente seguros após passo a passo através da NR12 eliminarmos os potenciais riscos.

\section{REFERÊNCIAS}

ATLAS, EQUIPE. Segurança e Medicina do MINISTÉRIO DO TRABALHO E EMPREGO. Trabalho, 1998.

\section{CAMPOS, A. Prevenção e Controle de Riscos,} 2012

CREASP. Disponível em: www.creasp.org.br/. Acesso em: 20 mar. 2015.

MARTINS, G. A. Manual para Elaboração de Monografias e Dissertações, 2014.

MORAES, M. V. G. Treinamento e Desenvolvimento Educação Corporativa, 2011.
Disponível em: http://portal.mte.gov.br/legislacao/ normas-regulamentadoras-1.htm. Acesso em: 12 fev. 2015.

OIT. Disponível em: <http://www.oit.com.br/>. Acesso em: 20 mar. 2015.

SISTEMA ABIMAC. Manual de Instruções e da Norma Regulamentadora NR 12. Disponível em: <www.abimaq.org.br/>. Acesso em: 12 fev. 2015. 